PAPER

\title{
Good medical ethics, justice and provincial globalism
}

\author{
Jennifer Prah Ruger
}

\section{Correspondence to Dr Jennifer Prah Ruger, Medical Ethics and Health Policy, Perelman School of Medicine at the University of Pennsylvania, 3401 Market Street, Suite 320, Philadelphia, PA 19104-3319, USA; jenpr@upenn.edu}

Received 31 August 2014 Revised 9 September 2014 Accepted 3 October 2014

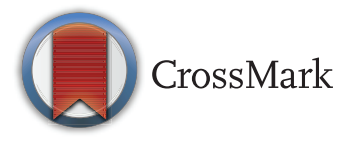

To cite: Ruger JP. J Med Ethics 2015;41:103-106.

\section{ABSTRACT}

The summer 2014 Ebola virus outbreak in Western Africa illustrates global health's striking inequalities. Globalisation has also increased pandemics, and disparate health system conditions mean that where one falls ill or is injured in the world can mean the difference between quality care, substandard care or no care at all, between full recovery, permanent ill effects and death. Yet attention to the normative underpinnings of global health justice and distribution remains, despite some important exceptions, inadequate in medical ethics, bioethics and political philosophy. We need a theoretical foundation on which to build a more just world. Provincial globalism (PG), grounded in capability theory, offers a foundation; it provides the components of a global health justice framework that can guide implementation. Under PG, all persons possess certain health entitlements. Global health justice requires progressively securing this health capabilities threshold for every person.

\section{INTRODUCTION}

Do massive global inequalities and other global health problems pose moral questions for the world community? While most in prosperous countries have adequate nutrition, housing, education and healthcare, extraordinary hardship afflicts those in impoverished countries who lack the most basic necessities. Where one is born-a morally arbitrary accident of birth—can condemn one to a brief and destitute existence, through no fault of one's own. Is rectifying this state of affairs a moral duty?

Global justice theories fall into four main perspectives: realism, particularism, social contractarianism and cosmopolitanism. Some offer no foundation for addressing global injustices, others approach it from their distinctive worldviews, but none provides a framework for answering comprehensively the deep moral questions global health problems pose.

Global and domestic institutions, groups and individuals need a theoretical foundation on which to build a more just world. Solutions to global health problems must derive from ethical values because ethical claims have the power to create greater understanding and commitment, to motivate, to delineate principles, duties and responsibilities and to hold actors responsible for achieving common goals. The provincial globalism (PG) framework ${ }^{1}$ offers a theoretical foundation. This approach seeks a world where all have the capability to be healthy. It argues that allowing individuals to die prematurely and suffer preventable morbidity when the global community could create the socioeconomic conditions necessary to support health is unjust.
Profoundly complex, health involves not just medicine and healthcare but also, inter alia, poverty, education and environment. The multiplicity of global actors-institutions, donors and nongovernmental organisations (NGOs) - exacerbates this complexity globally, as do international rules. All these factors elude national, not to mention individual, control. A moral framework and ethical guidelines are essential if health-sphere actors are to tackle global health problems effectively.

\section{PROVINCIAL GLOBALISM}

PG's components construct a theoretically grounded global health justice framework that in turn can guide implementation. Under PG, all persons possess certain health entitlements. Global health justice requires progressively securing this threshold level of health capabilities for all.

\section{Human flourishing and capabilities}

PG builds on the health capability paradigm, which argues, from an Aristotelian/capability perspective, that health capabilities are the basis for evaluating justice and efficiency in health policy. The Aristotelian/capability view grounds health capabilities' special moral importance, arguing that the capability to flourish is the proper goal of social and political activity. This universal obligation to human flourishing applies to all human lives, regardless of class, gender, race, ethnicity, community, nationality or state citizenship. Human flourishing encompasses capability, that which people are able to do and be and what possibilities they have. Capability includes human agency, an essential good to be ensured and promoted. Agency is key to flourishing because people flourish by shaping their own circumstances. Health agency encompasses decisions and choices about one's health.

Functionings are a person's achievements. Capability is the ability and freedom to achieve valued functionings. Examining capabilities, or individuals' abilities to function, even if they are not functioning at that level at a given time, reveals the deprivation and suffering many experience worldwide, helping to reveal which inequalities matter and why.

Both external and internal factors affect health capabilities. Some relate to human differences and the variation in converting to convert resources into functionings, others to the external environment and the extent to which a health system enhances or diminishes the ability to be healthy.

In PG, the goal of planning is a global and domestic distribution of the conditions enabling people to function in central ways. Accounting for 
human heterogeneity is important: justice requires aiding people in proportion to their degree of disadvantage, according to Aristotle's proportionality principle. Additionally, health capability determinants vary across societies, and assessing health capability inequalities must account for these differences.

PG assesses individual and group advantage and disadvantage against a threshold level of health capabilities and functionings; global health deficits are shortfalls from this threshold. But this obligation is not open ended: efficiency is also an important concern for justice and global health. The measure of global success lies in the extent to which our global and domestic arrangements succeed in enabling individuals to function best, given their natural circumstances, while using the fewest resources possible.

\section{Health capabilities}

Under PG, human flourishing justifies taking health capabilities as the global health policy objective. This perspective views health as both intrinsically and instrumentally valuable; all individuals should have equal capability to be healthy-to achieve good health and to avoid preventable morbidity and mortality. Health deprivations are inequalities in individuals' capabilities to function and direct threats to their well-being and agency. Such functional diminishments conflict with Aristotle's view that justice requires public policies to bring 'people as close to good functioning as their natural circumstances permit'. ${ }^{2}$

This approach seeks good health and the opportunities for it. A capabilities focus distinguishes between coercion and voluntary action: just looking at health outcomes alone (e.g., fertility rates), though one of this theory's key components and helpful for policy purposes, will not show what achieved these outcomes-coercive sterilisation, pregnancy termination or onechild policy laws, for instance. Importantly, health capabilities, through health agency, incorporate individual responsibility. Individual choices have personal and societal consequences. Individuals merit assistance in meeting health agency needs, and individuals owe their global and domestic communities the responsible exercise of health agency. Individual responsibility delineates the limits of social responsibility and underlines the causal influence of individual choices on health, as lifestyle and behaviour are health determinants.

PG values health capabilities and specifically central health capabilities-freedom from avoidable morbidity and premature death - as basic to other capabilities. Empirical evidence from the natural and social sciences shows the effects of disease on cognition and the ability to make decisions and engage in physical activities. Morally relevant health needs and health agency needs demand provision because they are essential for human functioning.

Distinguishing between central and non-central health capabilities allows prioritising for policy and institutional purposes. In PG, avoiding premature death and preventable morbidity claim priority in evaluating global health policies. Without these health capabilities, other capabilities-developing abilities, using talents and carrying out plans-are diminished if not entirely extinguished. Possessing these central capabilities is a universal human objective.

A set of health-related goods is key to ensuring these central health capabilities. These include medical services, public health and social support systems, adequate nutrition and safe, sanitary living and working environments.

\section{Transpositionality: a global view of health capabilities}

PG requires a global view of health capabilities. Universal agreement on all global health objectives is unnecessary, but PG requires a consensus on a minimal set of goals. The "positional objectivity' concept-that assessments of social affairs are objective if the individuals making them share similar circumstances or positions-suggests that a more 'transpositional' view could develop from 'synthesising different views from distinct positions'. ${ }^{3}$ This more global viewpoint could then help assess capabilities across communities. Health justice requires 'transpositional' viewpoints on important functionings.

History provides evidence of health's value in diverse contexts. The concept of free healthcare for all is over 3000 years old. Ancient Egyptian physicians provided free medical care to all citizens, and a form of insurance, pension and sick leave were available to workers building the pyramids. ${ }^{4}$ In 13th-century Egypt, many hospitals provided charitable healthcare; the largest, Cairo's Mansuri Hospital, could treat 8000 patients at once and provided free care to all regardless of gender, nationality, status or wealth. ${ }^{5}$ Throughout history, societies have eventually acknowledged health needs and developed health systems to meet them among their citizens.

Today, developing nations are increasingly providing universal care, following the pattern of many industrialised democracies and socialist countries. Middle-income countries like Brazil, Thailand and Mexico have achieved various degrees of universal health coverage, with countries like the Philippines, Vietnam and Indonesia not far behind. ${ }^{6}$ In Africa, Ghana, Rwanda, Kenya, Mali and Nigeria are moving towards universal coverage. Even China, India and South Africa are making strides; India hopes to achieve universal health coverage by 2022 and China by 2020 . $^{7}$ The historical record thus suggests a transpositional view.

\section{Health capability components: functionings, agency and needs}

Health capabilities represent the ability to achieve health-related functionings. Because health functionings map to health capabilities, they are effective indicators of health capabilities, which are not directly measurable. Health needs, in turn, map to health functionings. Health needs thus define what improving individuals' health capabilities require. How well we meet health needs measures objectively our success in improving health capabilities. The task, then, is to specify health needs as they relate to health functionings and health capabilities. Medical necessity and medical appropriateness are essential concepts.

Promoting central health capabilities depends upon health agency development. Health functionings are more valuable and more fully realised when they come about through one's own choice. Efforts to control HIV and AIDS, for instance, depend critically on individual self-management. Patients must seek and adhere to treatment and monitor CD4 counts and viral loads. Because individual behaviours cause much ill health, improving health depends on health agency. PG seeks to develop the ability to know when, how and what to do for one's health and the health of others-and the will to do it.

Collective health agency accompanies individual health agency. PG provides a foundation to identify and assign group rights and responsibilities. For example, groups within societies need collective health agency to demand necessary health conditions and to reshape health systems through political and civic engagement.

Health agency is good for human beings and for communities. Stable and consistent health agency involves conscientiousness about the impact of our behaviour on others' well-being, focusing on the fair distribution of goods and services. Taking more than one's fair share or taking others' share is both an individual and group health agency failure and an injustice. If individuals and groups possess this strong health agency, more sensible decisions will lead to less injustice. 


\section{From the individual to the global}

The PG framework begins with the health capability-health functioning and health agency - of every person worldwide as morally significant. It then works outward towards the necessary enveloping conditions.

The local nature of meeting needs requires beginning at the individual level and expanding outward. Telemedicine, foreign aid and global governance notwithstanding, ultimately a local provider in a local facility will provide medical attention to patients. Solving health problems requires a grasp of local realities. The neareradication of malaria in Eritrea demonstrates effective local programmes. No global health system will function optimally without on-the-ground systems to meet local populations' needs.

PG determines the health capabilities to which individuals are entitled and then allocates duties along a continuum from global to domestic spheres. Domestic and global commitments must align. A multilevel system is demonstrably the best approach for achieving global health objectives: successful polio eradication efforts in Latin America and the Caribbean offer one example. Those campaigns involved actors along the continuum: international entities such as the WHO, UNICEF and Rotary International; regional organisations such as the InterAmerican Development Bank and Pan American Health Organization; foreign national agencies such as the United States Agency for International Development, Centers for Disease Control and Prevention and the Canadian Public Health Association; and national structures such as ministries of health and other sectoral ministries. ${ }^{7}$

National government efforts have achieved notable health successes, such as Thailand's '100 percent condom program' for HIV prevention, Sri Lanka's maternal mortality reduction and Chile's Haemophilus influenzae type b immunisation programme. ${ }^{7}$ Global cooperation is still necessary, however, to produce valuable collective goods, such as disease surveillance and global standards. Individuals, groups and nation-states must do their share of the work to create such goods.

\section{Principles and measurement in health equity theory: shortfall equality}

Some PG components are easier to measure empirically (e.g., health functionings) than others (e.g., health agency), but measurement theory undergirds the PG approach.

The health capability paradigm employs the 'shortfall equality' concept, setting a norm or threshold against which to assess health equity. It considers the worse-off and the need for proportional allocation, and it incorporates equality, but not full equality, of health outcomes or access to healthcare.

At the country or group level, measuring shortfall equality-comparing the actual achievement of a given policy or system with the chosen benchmark level—can show quantitatively how much a society or group has realised its health potential and how much remains unrealised. This construct points the way towards public policies that bring each individual's health functioning up to a set level (within the limits of that person's circumstances), but do not lower the general population's health functioning beneath the norm.

\section{Principles for allocating and prioritising responsibilities: functions and capabilities}

Who is responsible for realising health equity at the global level? What duties and responsibilities do global and state actors and institutions have for realising health equity at the global level? PG analyses the party or parties who are functionally able to correct and prevent injustices through their roles, resources and capabilities and allocates responsibilities accordingly.
Individuals and groups at the global, national and local levels make voluntary commitments to share resources and relinquish some autonomy to address health problems collectively; institutions and agents accept functional roles in addressing health issues. Specific duties follow from general duties, and a provincial consensus on these obligations must accompany a general global consensus; otherwise, parties responsible for specific duties (e.g., nation-states) will not fully embrace and fulfil them. Voluntary engagement is important because duties cannot be forcibly imposed.

Reducing global health disparities and containing externalities involves four key functions: (i) redistribution of resources within and among societies; (ii) related legislation and policy (progressive taxation, equitable and efficient risk pooling and redistributive expenditure); (iii) public regulation and oversight and (iv) creation and distribution of public goods.

These key functions must occur at both global and national levels, but the nation-state is the primary channel through which individuals and groups accomplish these duties. The sovereign state has further legitimacy in taking on this role-perhaps the only current legitimacy-given its central function in raising and redistributing revenue and creating and implementing policies and laws; we have no global government. National measures promoting central health capabilities gain legitimacy through democratic self-governance and the state's authority as the functional structure through which individuals cede some autonomy and resources to pursue common goals. PG also assigns duties and responsibilities to other domestic and global actors and institutions.

\section{Ethical commitments, public norms}

PG accepts that societies must agree upon health equity goals if public action is to follow. Policy measures will require ethical commitments evolving from the inculcation of fundamental health equity norms. Without ethical commitments, organising socially and redistributing resources is not possible. Once individuals internalise these positive norms, they freely accept the obligations entailed. States too must internalise these norms: self-interested behaviour by states might advance their geopolitical agendas in the short term but often undermines international organisations. While certain areas of life might be free from moral interventions, health is not one of them. Health is too basic and the stakes are too high.

\section{Institutions and actors}

In PG, sustainability is key: it seeks a new global health equilibrium that remedies current global health problems and structures the global health enterprise to address emerging threats going forward. Primary responsibilities in domestic and international health policy and law fall to nation-states. The limits of national obligations then reveal where international obligations lie. These limits show where collaborations can bring together state and international players, NGOs, communities, businesses, foundations and individuals.

\section{Beyond the nation-state: global obligations}

Global health functions promote global public health goodsmeasures that benefit all countries but lie beyond individual governments' and independent groups' reach. While no global institutions have the authority and power of global government, a reformed global health architecture could better manage health and expand health justice. Duties in five categories, in particular, fall to global institutions: (i) generating and sharing knowledge and information; (ii) empowering developing-country players in national and international fora; (iii) providing technical assistance, financial aid and global advocacy for fair, functional 
health systems; (iv) reducing redundancies in international health activities and (v) creating global public goods.

\section{Responsibilities of the nation-state}

Meeting health and health agency needs requires functioning local and national systems. The sovereign nation-state has central roles in raising and redistributing revenue, enacting and implementing policy and enforcing policy through legal systems -functions no global structures exist to perform.

Nation-states thus are primarily responsible for fostering health capabilities because they are best positioned to provide systems and services-healthcare, public health and health literacy goods, and proximal and controllable health determinants, including nutritious and safe food, potable water, sanitation and adequate living conditions. These systems must ensure quality health-related goods and services. Every person, when confronted with serious symptoms or conditions, must be able to obtain care. Stewardship of the health system is critical and includes public health surveillance systems, which feed into the international community's global surveillance system.

Providing medically necessary and medically appropriate healthcare and public health services for all is a matter of justice, nationally and globally. When national governments fall short, justice summons the global community to work for health equity even while respecting countries' self-determination. PG aspires to selfactualised societies in which governments and peoples commit fully to ensuring central health capabilities for all. The global community must provide assistance and oversight when incompetent states fail to deliver. PG does not encourage the use of force, coercion or sanctions because such measures often cause more harm than good, especially among populations suffering most. But the power of social movements and their influence in changing norms and governance through the value formation process is an important area for further study. Movements for racial justice, women's rights and environmental protection, among many others, prove that norms can change dramatically, with far-reaching effects.

\section{Finding consensus among plurality: incompletely theorised agreements}

In a multifarious global community, diverse actors, values and viewpoints make achieving a consensus on health morality challenging, but agreement on fundamental health morality principles can take shape using an incompletely theorised agreement. Where universal agreement is not possible, the incompletely theorised agreement approach can bring people together on a specific issue-maintaining central health capabilities like mobility, for instance-even absent agreement on broader equality.

Behavioural ethics teaches us that proper information, free choice, transparency, equality and public debate can aid in finding convergence among differing viewpoints. There exist 'values that can be justified to all persons when those persons' reasoning is not distorted by self-interest, factual mistakes, complacency and so on.8 We are capable of making reliable moral judgements when we respect and value all persons' interests equally from a transpositional viewpoint. One study examined a group deliberative setting in which participants discussed people who are uninsured or are vulnerable to losing insurance. Participants received factual information about the impact of being uninsured not just on the uninsured themselves, but on insured people, businesses and communities. From this discussion, participants were more willing to contribute some of their healthcare dollars to cover the uninsured, especially children. ${ }^{9}$ Starting with a community engagement and education methodology and continually revising, it can protect moral arguments from distortion and bias.

\section{CONCLUSION}

PG provides components of a global health justice theory embodying a moral duty to promote central health capabilities grounded in the principle of human flourishing. It allocates responsibility to fulfil this duty among global and national actors and individuals themselves, based on principles of functional requirements and needs, health agency and voluntary commitments. It recognises the moral importance and political significance of self-determination and the nation-state as a political unit. It puts forth health agency both as an end inherent to health capability and as a principal means for achieving it. It balances global and national health systems. It embraces norm change, value formation, persuasion and social movements.

Competing interests None.

Provenance and peer review Commissioned; internally peer reviewed.

\section{REFERENCES}

1 Ruger JP. Global health justice. Public Health Ethics 2009;2:261-75.

2 Nussbaum MC. Nature, function, and capability: Aristotle on political distribution. In Patzig G. ed. Aristoteles' "Politik". Göttingen, Germany: Vandenhoeck \& Ruprecht, 1990:155.

3 Sen A. Positional objectivity. Philos Pub Affair 1993;22:130.

4 Kelly K. The history of medicine: early civilizations: preshistoric times to 500 CE. New York, New York: Infobase Publishing, 2009.

5 Sabra A. Poverty and charity in medieval Islam: Mamluk Egypt, 1250-1517. Cambridge, UK: Cambridge University Press, 2000:69-80.

6 Rodin J, de Ferranti D. Universal health coverage: the third global health transition? Lancet 2012;380:861-2.

7 Levine R, Kinder M. Millions saved: proven successes in global health. Washington, DC: Center for Global Development, 2004.

8 Caney S. Justice beyond borders: a global political theory. Oxford, UK: Oxford University Press, 2005:49.

9 Goold SD, Green SA, Biddle AK, et al. Will insured citizens give up benefit coverage to include the uninsured? J Gen Intern Med 2004;19:868-74. 